Research Article

\title{
Exploring the Feasibility of Ventilation without Shafts for an Ultralong Subsea Tunnel in the Bohai Strait Channel
}

\author{
Yimin Wu, Peng Xu (D, Weiming Liang, Shuai Shao, Kaixun Hu, Jiawei Zhang, Haoran Wu, \\ and Guangzheng Zhuang
}

School of Civil Engineering, Central South University, Changsha, Hunan 410075, China

Correspondence should be addressed to Peng Xu; xupeng1033@csu.edu.cn

Received 3 July 2021; Accepted 28 September 2021; Published 8 October 2021

Academic Editor: Zhuang-Zhuang Liu

Copyright ( $\odot 2021$ Yimin Wu et al. This is an open access article distributed under the Creative Commons Attribution License, which permits unrestricted use, distribution, and reproduction in any medium, provided the original work is properly cited.

\begin{abstract}
The Bohai Strait Channel (BSC) is a strategic infrastructure project connecting the Shandong Peninsula and northeastern China. One challenge related to building the BSC tunnel portion is that ventilation shafts cannot be constructed due to certain limitations, which leads to a barrier for ventilation design. To explore the feasibility of ventilation without shafts, we first compare the tunnel ventilation design methods in China and the European Union. We also present the development process of emission standards, base emission rates, and design concentration values. Then, a new ventilation calculation for the BSC tunnel with reference values from the World Road Association (PIARC) is presented. The results show that the longitudinal ventilation design without shafts is feasible under normal traffic conditions when adopting values designed by PIARC under both the Chinese method and the European method. Furthermore, the influence of new energy vehicles and the necessity of ventilation rate on ventilation design are discussed. We suggest considering new energy vehicle fire situations and ignoring the ventilation rate for BSC tunnels. We hope to provide a strong reference for the ventilation design of BSC tunnels and for the improvement of relative ventilation codes in China.
\end{abstract}

\section{Introduction}

The Bohai Strait Channel (BSC) and the Qiongzhou Strait Channel are two metastrategic projects that are intended to create a convenient and comprehensive coastal traffic network in China. After years of continuous construction, coastal high-speed railway and expressway lines have been completed which connect most economic areas in China. However, the Bohai Strait and Qiongzhou Strait represent two breakpoints of the coastal transportation artery, which affects the social and economic benefits of the whole system [1], as shown in Figure 1.

The BSC tunnel portion will be constructed in the Laotieshan Course, which is the essential shipping channel in the Bohai Sea. Building ventilation shafts will affect regular shipping, whereas, due to military limitations, no infrastructure at the sea surface is permitted. Therefore, a subsea tunnel scheme without shafts crossing the Laotieshan Course should be designed [2-4].
The narrowest width of the Laotieshan Course is $48 \mathrm{~km}$, which is the shortest possible length of the BSC tunnel. This challenging distance is, therefore, far beyond the length of the ventilation and disaster prevention mechanisms of other extralong tunnels in the world. For example, the Laerdal tunnel, which is the longest single line highway tunnel in the world with a length of $24.51 \mathrm{~km}$, has adopted longitudinal ventilation with a ventilation shaft situated $6.51 \mathrm{~km}$ from the north entrance [5]. The Zhongnanshan tunnel [6] in Qinling Mountain, which is the largest separated highway tunnel in the world with a length of $18.02 \mathrm{~km}$, uses three vertical ventilation shafts, whose maximum length of segmented ventilation is $5494 \mathrm{~m}$. In addition, other superprojects, such as the Gotthard Road tunnel [7], the Frejus tunnel [8, 9], the Kanetsu tunnel, and the Plabutsch tunnel [10], have all adopted the shaft ventilation method, as shown in Table 1. The segmented ventilation lengths of these tunnels do not exceed $6 \mathrm{~km}$. Moreover, none of the mentioned projects faced the challenge of abandoning ventilation shafts in a 


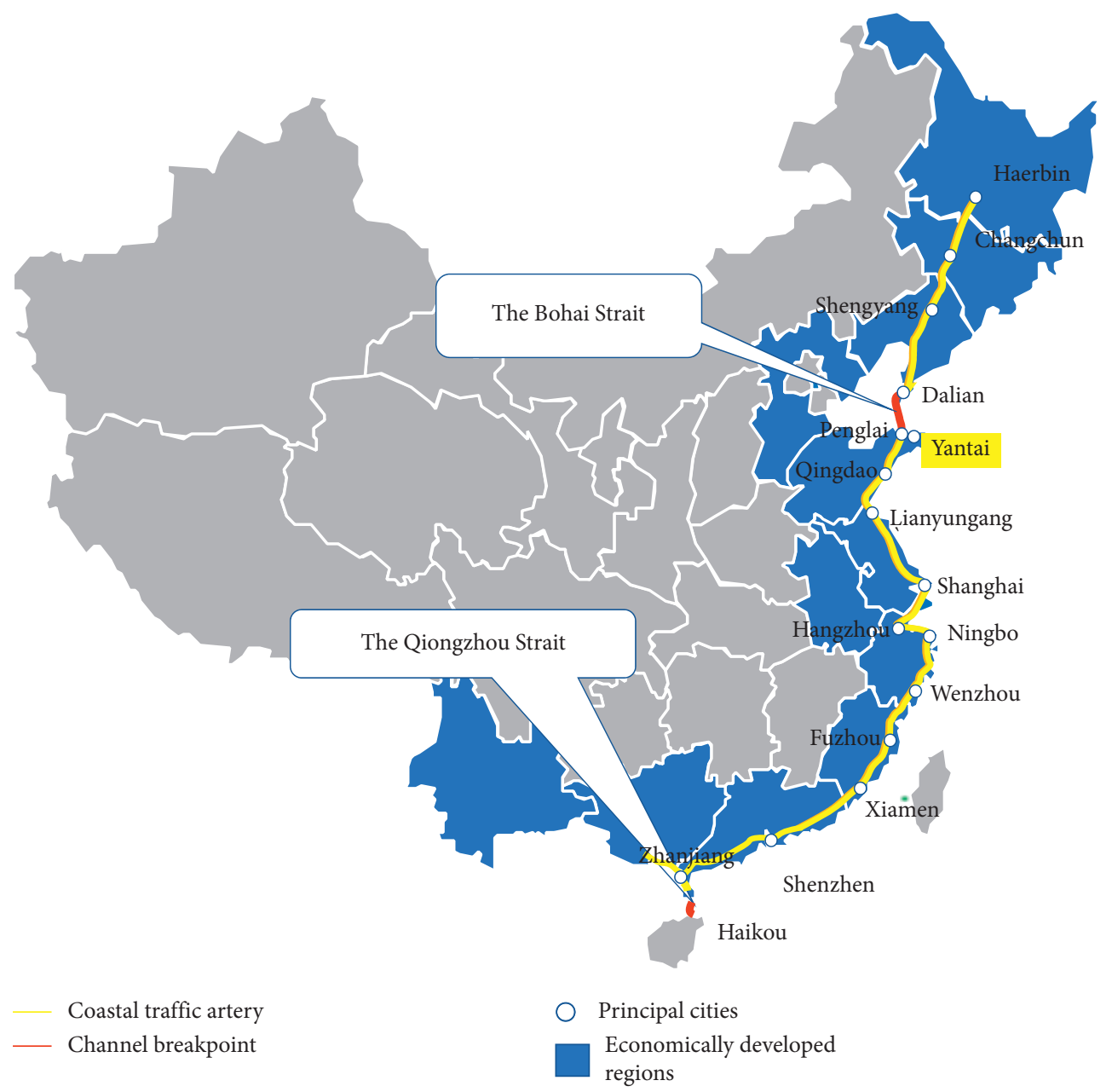

FIGURE 1: Channel breakpoint in coastal traffic artery.

TABLE 1: Ventilation of extralong tunnels around the world.

\begin{tabular}{|c|c|c|c|c|c|}
\hline Name & Country & Length $(\mathrm{km})$ & Type & $\begin{array}{l}\text { Max ventilation } \\
\text { length }(\mathrm{m})\end{array}$ & Ventilation pattern \\
\hline Laerdal tunnel & Norway & 24.5 & $\begin{array}{c}\text { Bidirectional } 1 \text { tube with } 2 \\
\text { lanes }\end{array}$ & 6510 & Segmented longitudinal \\
\hline $\begin{array}{l}\text { Gotthard Road } \\
\text { tunnel }\end{array}$ & Switzerland & 16.9 & $\begin{array}{c}\text { Bidirectional } 1 \text { tube with } 2 \\
\text { lanes }\end{array}$ & 5658 & Semitransverse \\
\hline Frejus tunnel & Italy & 12.9 & $\begin{array}{c}\text { Bidirectional } 1 \text { tube with } 2 \\
\text { lanes }\end{array}$ & $\sim 4000$ & Semitransverse/longitudinal \\
\hline $\begin{array}{l}\text { Zhongnanshan } \\
\text { tunnel }\end{array}$ & China & 18.02 & $\begin{array}{c}2 \text { tubes with } 2 \text { lanes per } \\
\text { direction }\end{array}$ & 5494 & Segmented longitudinal \\
\hline Kanetsu tunnel & Japan & $11.055+11.926$ & $\begin{array}{l}2 \text { tubes with } 2 \text { lanes per } \\
\text { direction }\end{array}$ & 3738 & $\begin{array}{c}\text { Longitudinal with electrostatic } \\
\text { precipitator }\end{array}$ \\
\hline Plabutsch tunnel & Austria & $10.085+9.913$ & $\begin{array}{l}2 \text { tubes with } 2 \text { lanes per } \\
\text { direction }\end{array}$ & $\sim 2500$ & Transverse \\
\hline
\end{tabular}

$48 \mathrm{~km}$ tunnel. The challenge of this project is to investigate whether a longitudinal ventilation scheme for a $48 \mathrm{~km}$ subsea tunnel is feasible.

This study carried out a trial calculation of the air demand and wind speed in the tunnel according to the Guidelines for Design of Ventilation of Highway Tunnels JTG/T D70/2-02-2014 (which we refer to hereafter as the "Chinese code"). The results showed that the air demand to dilute smoke and dust is far greater than that of CO; the maximum air demand is projected to be $1927 \mathrm{~m}^{3} / \mathrm{s}$ in 2040 in the short term, while the air demand is projected to be $2272 \mathrm{~m}^{3} / \mathrm{s}$ and $2608 \mathrm{~m}^{3} / \mathrm{s}$ in 2050 and 2060 , respectively, in the long term. The wind speed meeting the short-term air demand is $18.7 \mathrm{~m} / \mathrm{s}$, which is far greater than the maximum wind speed of $12 \mathrm{~m} / \mathrm{s}$ specified in the Chinese code. This means that the longitudinal ventilation model of the BSC 
tunnel cannot meet the requirements in the specifications, thus hindering the feasibility of the construction of the Bohai Strait Channel.

To provide support for the feasibility assessment of the project, we used the base emission rate under the Euro 6 emission standard to calculate the longitudinal ventilation scheme and analyze the feasibility of the BSC tunnel. The reasons for this were as follows: (1) by comparing the ventilation codes of China and the European Union (EU), we found that the base emission rate in the Chinese code is out of date and not applicable to the ventilation calculation of the BSC tunnel; (2) by comparing the emission standards of China and EU, we found that the China 6 emission standard is basically the same as the Euro 6 emission standard. Thus, we used the base emission rate under the Euro 6 (China 6) emission standard as the base emission rate of the target year, and the calculation results were conservative. On the basis that the calculation results meet the requirements of the longitudinal ventilation scheme, we also discuss the influence of the increase in proportion of new energy vehicles and that of the ventilation rate on ventilation design and fire rescue, and we hope to provide support for feasibility research on the Bohai Strait Channel.

\section{Project Overview}

In the past 10 years, the BSC project has attracted increased attention and support from academicians [11-14]. Many meetings have been hosted to discuss its feasibility. Meanwhile, many scholars have also participated in exploring various topics about the BSC $[15,16]$, such as the route scheme, the economic effects [17], and the possibility of an earthquake. All of this work has pushed forward the implementation of the BSC. In 2019, a key strategic consulting project of the BSC was established in the Chinese Academy of Engineering (no. 2019-ZD-7), which was named the Preliminary Strategic Research of Bohai Strait Channel Project. The ventilation design of the BSC tunnel is based on the plans presented in the consulting project. Exploring the flexibility of ventilation design is also an essential topic of the consulting project.

2.1. Construction Plans. The four construction plans of the Bohai Strait Channel in the "Preliminary Strategic Research of Bohai Strait Channel Project" are shown in Figure 2, and all of them adopt bridge-tunnel strategies. In these plans, several sea-crossing bridges are built relying on the islands in the southern section. A subsea tunnel is constructed in the northern course to meet the requirements of shipping and military activities. The first route through the western port of Changshan Island is $111 \mathrm{~km}$ long (the red line). The second route is $121 \mathrm{~km}$ long through the beacon tower of Daheishan (the purple line). Another route through the beacon tower of Changshan Island is $115 \mathrm{~km}$ long (the light blue line). The last route though the eastern port of Cheyou Island is $108.5 \mathrm{~km}$ long (the dark blue line). Although there are different sea-crossing bridges, the subsea tunnel lying to the south is a fixed plan. In these plans, the shortest tunnel length is $48 \mathrm{~km}$ along the route through the west port of Changshan Island. Therefore, in this manuscript, ventilation is discussed based on a subsea tunnel.

Highway and high-speed railway transportation is required in the construction of the BSC. According to the proposed tunnel boring machine excavation method, the cross section of the subsea tunnel under the Laotieshan Course is a circle. After a comprehensive comparison considering operation safety, disaster prevention, rescue evacuation ability, and so on, the recommended layout plans of the cross section involve the scheme of two single-track railways and two highways, which are presented in "Preliminary Strategic Research of Bohai Strait Channel Project," as shown in Figure 3.

The railway tunnel and the highway tunnel are connected by cross-passages, which are used as emergency passages for each other. The inner diameter of the highway tunnel is $13.2 \mathrm{~m}$, and the section area is $136.8 \mathrm{~m}^{2}$. The highway tunnel's design speed is $80 \mathrm{~km} / \mathrm{h}$, which bears the function of passenger transport and freight transport. For railway tunnels, their design speed is $250 \mathrm{~km} / \mathrm{h}$, and they only need to be dedicated to carrying passenger transport. The project's construction period is expected to be 15 years; thus, it is expected to be finished in 2035 .

2.2. Ventilation Challenges. Designing an ultralong tunnel without ventilation shafts is the only option. During the feasibility assessment period, the Highway Design Institute of China Communications Construction Company predicted the traffic volume of the BSC in the short term (2035-2040) and long term (2041-2060), as shown in Table 2.

In the ventilation calculation, two $6.6 \mathrm{~km}$ long sections with $\mathrm{a} \pm 1.5 \%$ slope at the entrance and exit of the tunnel and one $34.8 \mathrm{~km}$ long section with a gradient of $0 \%$ in the middle were adopted. The clear area of the tunnel accounts for $102 \mathrm{~m}^{2}$. According to Guidelines for Design of Ventilation of Highway Tunnels JTG/T D70/2-02-2014 [18] (we termed it Chinese codes), the base emission rate used in the trial calculation in Section 1 is shown in Table 3.

The base emission rates of Chinese codes take 2000 as the base year. China issued a series of emission standards to limit vehicle emissions in 2000-2020. The actual emissions of smoke and harmful gases have been greatly reduced, but the base emission rates corresponding to the emission standards have not been updated in time. Meanwhile, the calculation method of the base emission rate in the target year and the base emission rate in Chinese standards do not match the development of emission standards and the actual vehicle emissions. Accordingly, the results of the trial calculation cannot meet the requirements of the code, as mentioned in Section 1. In the next sections, we compare the calculation methods in China and Europe, present the updated process of emission standards, and discuss the base emission rate. This process may help to determine a breakthrough in the ventilation design calculations for the BSC tunnel. 


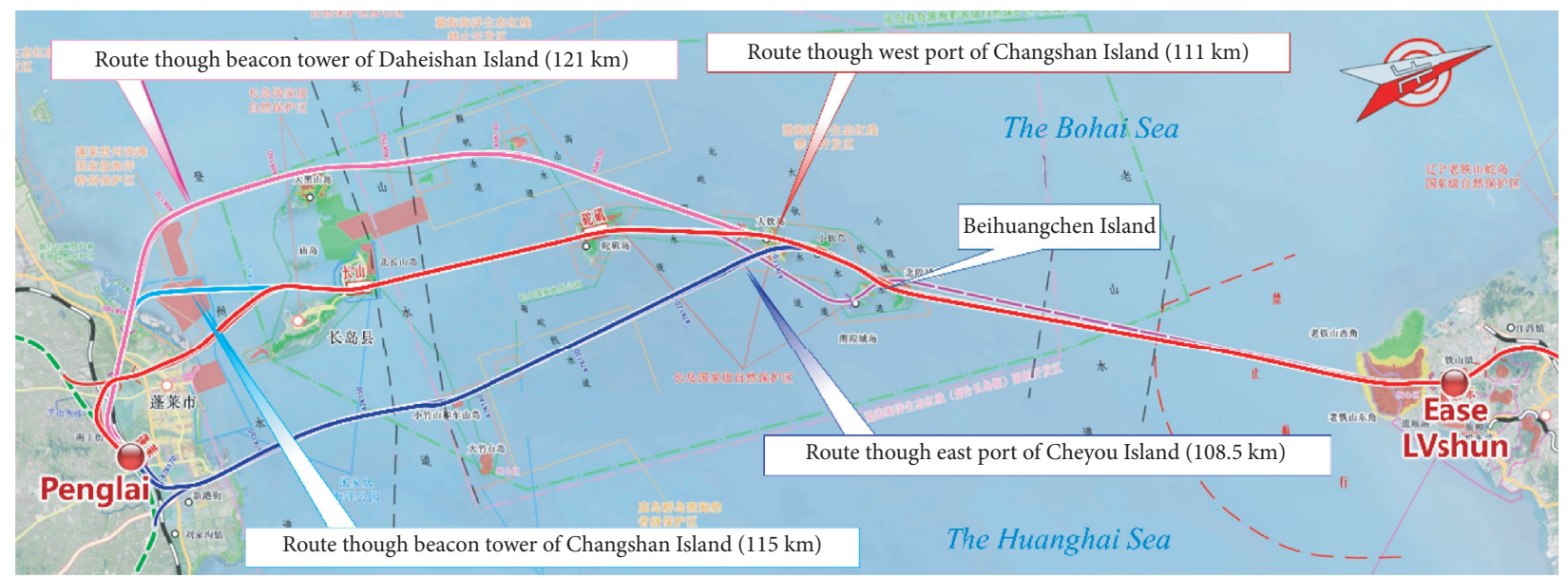

Figure 2: Route plans of the Bohai Straits Channel.

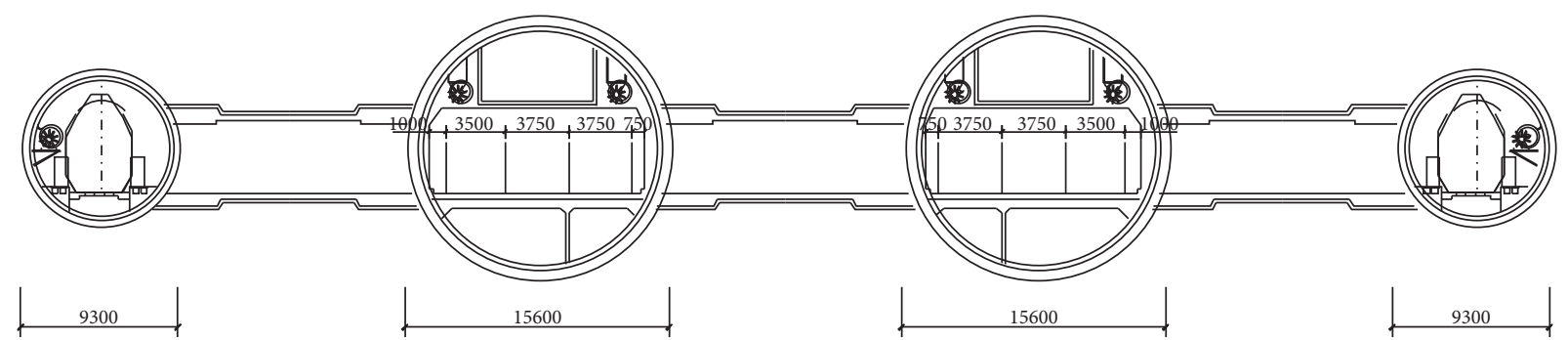

FIGURE 3: Recommended layout plan of the tunnel cross section $(\mathrm{cm})$.

\section{Comparison of the Ventilation Calculation Method}

The purpose of tunnel ventilation is to dilute the smoke and $\mathrm{CO}$ emitted by vehicles so that the air in the tunnel can meet the requirements of safety standards, health standards, and driving comfort. The main parameters of ventilation calculation include pollutant emissions, design concentration, and air demand.

3.1. Calculation Methods. The calculation of CO emissions in Chinese codes is as

$$
Q_{\mathrm{CO}}=\frac{q_{\mathrm{CO}} f_{a} f_{d} f_{h} f_{i v} L \sum_{m=1}^{n}\left(N_{m} f_{m}\right)}{3.6 \times 10^{6}},
$$

where $Q_{\mathrm{CO}}$ is the volume of CO emissions in the whole tunnel $\left(\mathrm{m}^{3} / \mathrm{s}\right)$ and $q_{C O}$ represents the CO base emissions for the target year $\left(\mathrm{m}^{3} /(\mathrm{veh} \cdot \mathrm{km})\right)$. The calculation is based on the base emissions rates of $0.007 \mathrm{~m}^{3} /(\mathrm{veh} \cdot \mathrm{km})$ with an annual reduction of $2 \%$ starting from 2000 . For example, $q_{c o}$ of the target year 2020 is $0.007 \times(1-0.02)^{20} \mathrm{~m}^{3} /(\mathrm{veh} \cdot \mathrm{km})$. Furthermore,

$f_{a}$ is the road condition factor,

$f_{d}$ is the vehicle density factor,

$f_{h}$ is the altitude factor,

$f_{m}$ is the vehicle type factor, $f_{i v}$ is the slope-speed factor,

$L$ is the length of the tunnel (m),

$N$ is the number of vehicles,

$N_{m}$ is the traffic volume of one type of vehicle (veh/h).

In the design standards of the European Union [19], the calculation of $\mathrm{CO}$ emissions is as

$$
G_{\text {tun }}=\sum_{k=1}^{N_{\text {lane }}} \sum_{j=1}^{N_{\text {sec }}} G_{\text {sec }, j},
$$

where $G_{\text {tun }}$ is the volume of CO emissions in the whole tunnel(g/s), $N_{\text {sec }}$ is the number of longitudinal sections of tunnel, $N_{\text {lane }}$ is the number of tunnel lanes, and $G_{\mathrm{sec}, j}$ represents the $\mathrm{CO}$ emissions in a single lane with a longitudinal slope:

$$
\begin{aligned}
G_{\mathrm{sec}} & =\sum_{h=1}^{N_{\mathrm{cat}}} g_{\mathrm{fac}, i} n_{\mathrm{veh}, i}, \\
g_{\mathrm{fac}, i} & =g_{\mathrm{cat}} \cdot f_{t} \cdot f_{m} \cdot f_{a}+g_{\mathrm{non}-\mathrm{ex}},
\end{aligned}
$$

where $g_{\text {fac }, i}$ is the base emissions rate of a certain vehicle under different speeds and different slopes $(\mathrm{g} / \mathrm{s})$ taking 2018 as the base year. Furthermore,

$n_{\mathrm{veh}, i}$ is the traffic volume corresponding to the vehicle $f_{t}$ is the time factor, taking 2018 as the base year 
Table 2: Forecast traffic volume for the Bohai Strait Channel (veh/d).

\begin{tabular}{lcccc}
\hline Years & Passenger cars & \multicolumn{2}{c}{ Light-duty vehicles } & Heavy goods vehicles \\
& & Gasoline & Diesel & 5710 \\
2035 & 14270 & 149 & 149 & 6567 \\
2040 & 16894 & 171 & 171 & 7736 \\
2060 & 22970 & 208.5 & 208.5 & 8875 \\
\hline
\end{tabular}

TABle 3: Target emission rates based on Chinese codes.

\begin{tabular}{|c|c|c|c|c|}
\hline \multirow[t]{2}{*}{ Situation } & \multicolumn{2}{|c|}{$\begin{array}{l}\text { Base emission rate of CO } \\
\left(\mathrm{m}^{3} /(\text { vel } \cdot \mathrm{km})\right)\end{array}$} & \multicolumn{2}{|c|}{$\begin{array}{l}\text { Base emission rate of smoke } \\
\text { and dust }\left(\mathrm{m}^{2} /(\mathrm{vel} \cdot \mathrm{km})\right)\end{array}$} \\
\hline & 2000 & 2035 & 2000 & 2035 \\
\hline Normal traffic operations & 0.007 & 0.00382 & 2.0 & 1.091 \\
\hline Congested traffic operations & 0.015 & 0.00818 & & \\
\hline
\end{tabular}

$f_{m}$ is the mass factor

$f_{a}$ is the altitude factor

$g_{\text {non-ex }}$ represents the nonexhaust emissions, such as tire wear particles

Comparing equations (1) and (2), we find that the principle of calculating pollutant emissions is the same for Chinese codes and EU codes. Both of them calculate the annual target emissions based on the base emission rate and compute the total pollutant emissions according to the traffic composition, traffic volume, and other tunnel factors.

However, the difference is the base emission rates. The base emission rate of $\mathrm{CO}$ in Chinese codes is $0.007 \mathrm{~m}^{3} /(\mathrm{veh} \cdot \mathrm{km})$, taking 2000 as the base year. However, in EU codes, the emission rate, $g_{\text {cat }}$, for each vehicle type under different slopes and speeds is provided in the standards, which takes 2018 as the reference year and adopts $\mathrm{g} / \mathrm{s}$ as the unit. The base emission rate in EU codes considers the slope factor and vehicle type. Thus, we need to check the base emission rate of different vehicles under different longitudinal slope conditions during calculation. In contrast, the $\mathrm{CO}$ base emission rate in Chinese codes applies to all vehicle types.

Generally, the calculation method in Chinese codes is relatively convenient, but the base rates are usually out of time. Therefore, the calculation results might be beyond the real requirements and result in waste. Thus, it is necessary to calculate the BSC tunnel's ventilation by applying the updated emission rates and considering the effects of slope and vehicle types.

The conversion of the base emission rates from EU codes to Chinese codes is as

$$
q_{\text {Euro-Chi }}=\frac{g_{\text {cat }} \cdot f_{t}}{\rho_{c o} \cdot v},
$$

where $q_{\text {Euro-Chi }}$ is the conversed base emission rate $\left(\mathrm{m}^{3} /\right.$ $(\mathrm{veh} \cdot \mathrm{km})), v$ is the design speed, $\mathrm{km} / \mathrm{h}$, and $\rho_{c o}$ is the density of $\mathrm{CO}, \mathrm{kg} / \mathrm{m}^{3}$.
According to the calculation method in Chinese codes, the new calculation equation using the converted base emission rate will not need to consider the slope factor and vehicle type factor, while the emissions of different longitudinal slope sections must be computed as

$$
Q_{\mathrm{CO}}=\sum_{i=1}^{k} L_{i} \cdot Q_{\mathrm{CO}, i}
$$

where $k$ is the number of longitudinal sections, $L_{i}$ is the length of longitudinal section $(\mathrm{m})$, and $Q_{\mathrm{CO}, i}$ is the $\mathrm{CO}$ emission of the corresponding longitudinal slope. The calculation is according to the following equation:

$$
Q_{\mathrm{CO}, i}=\frac{f_{d} \cdot f_{a} \cdot f_{h} \sum_{m=1}^{n}\left(q_{\text {Euro-Chi }} \cdot N_{m}\right)}{3600 \times 10^{6}} .
$$

\subsection{Permitted Maximum Concentration. The requirements} for smoke and $\mathrm{CO}$ concentration in a tunnel are useful to ensure safety and comfort of drivers and passengers. The World Road Association (PIARC) set the design concentration limitation of smoke and dust as $0.0075 \mathrm{~m}^{-1}$ in 1995 [20] and has decreased it to $0.005 \mathrm{~m}^{-1}$ in recent years (Figure 4(a)). Similarly, the design concentration of $\mathrm{CO}$ has been reduced from $150 \mathrm{ppm}$ to $70 \mathrm{ppm}$ in recent years through several adjustments, as shown in Figure 4(b).

In Chinese codes implemented in 2014, the design concentration of smoke and dust is $0.065 \mathrm{~m}^{-1}$, which is close to the value designed by PIARC in 1991. Similarly, CO's design concentration is $100 \mathrm{ppm}$ in the Chinese code for tunnels over $3000 \mathrm{~m}$, which is equivalent to the value designed by PIARC in 1995. Thus, the design values in Chinese codes are very conservative and even out of date. On the other hand, the BSC will be constructed in 2035, which is still 15 years away. If we accept the design values in Chinese codes that come from the last century, it is hard to ensure future traffic safety and health standards in the 


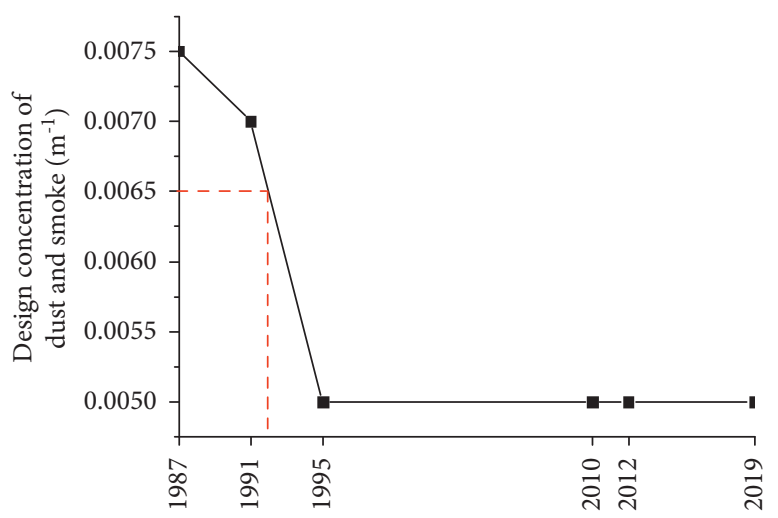

(a)

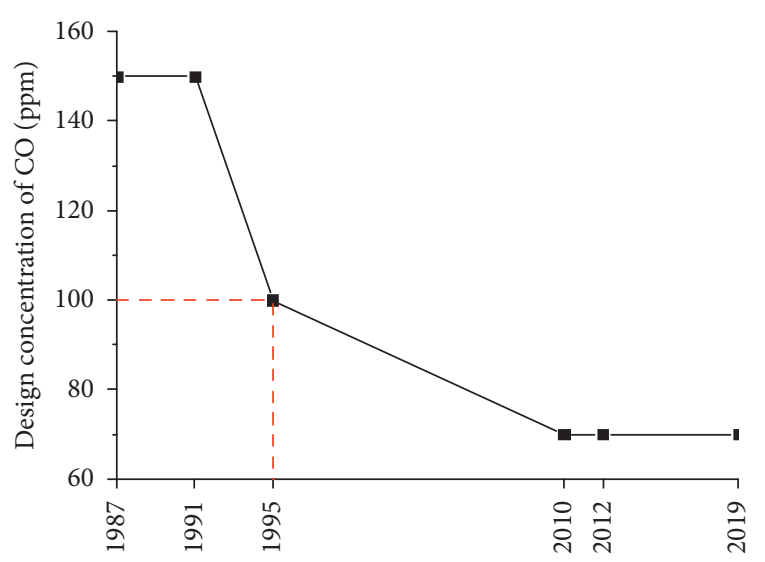

(b)

Figure 4: Development of the design concentration values in PIARC. (a) Development of the dust and smoke design values. (b) Development of $\mathrm{CO}$ design values.

tunnel. Therefore, we think we should be strict and adopt smaller design concentration values for the BSC tunnel.

\section{Recommended Base Emission Rates}

The base emission rate is a specific quantity of pollutants (gas or aerosol) emitted by a vehicle of emission standards during its journey under a unit of distance or specific speed. The measurement of the base emission rate is usually made after the implementation of emission standards.

4.1. The Development of Emission Standards. Since the 1990s, governments have gradually taken measures to control vehicle pollutants and have issued a series of emission standards. The existing automobile emission regulations are mainly divided into three systems: the European system, the American system, and the Japanese system. Other countries establish their emission regulations by referring to the three systems. China began to implement its first emission standards in 1983. Since 2001, China's automobile emission standard has referred to the European emission regulation system. To date, Europe and China have released six stages of pollutant emission limits for passenger cars. Their development process is shown in Table 4.

As shown in Table 4, China implemented the China 1 emission standard in 2001, which was nine years later than PC Euro 1. In general, China lags behind the EU by 5-10 years for the same stage of emission standards. However, China caught up in 2020, when both areas adopted six-stage emission standards.

In the same stage of emission standards, the limit values of harmful gases in China and Europe are almost the same. With updating emission standards, more indicators are included in such standards, and the limits of each indicator become stricter. By 2023, China will implement China 6b. In this policy, the CO limit and hydrocarbon compound limit will be $50 \%$ lower than those of Euro 6, and other values will be at least 30\% lower than those of Euro 6. China has caught up with European emission standards in the past 20 years and will implement more stringent emission laws than EU standards in the future.

The renewal of the emission standard will drive the development of the automobile industry, and the emissions from vehicles will be clearer than before in return. Hence, the PIARC usually updates the base emission rates approximately every 5 years, thereby ensuring that the ventilation design is based on the latest emission situation. The latest release is Vehicle Emissions and Air Demand for Ventilation 2019 (we abbreviated it as VEADV2019).

Unfortunately, there are only two standards for calculating ventilation in China. The last standard updated 7 years ago still relies on stale data that cannot reflect the development of Chinese emission standards. Therefore, instead of simply choosing values from Chinese codes, we should consider the fast development of emission standards and choose a more suitable base emission rate for the BSC tunnel's ventilation design.

4.2. Base Emission Rate for the BSC Tunnel. In Chinese codes, the calculation of the base emission rate for a target year is based on the base emission rate with an annual reduction of $2 \%$ starting from 2000 , and the maximum reduction period shall not exceed 30 years. The base emission rate in the code is no longer applicable to the ventilation design of the BSC, as discussed in the previous section. However, no new base emission rates have been issued based on China 5 or China 6 emission standards. It is, therefore, impossible to obtain a suitable emission rate for the BSC tunnel from the current China codes.

Fortunately, the base emission rates under Euro 6, the values of which are the same as the values of China 6, are provided in VEADV2019, which was designed by the PIARC in 2019. From now on, all newly sold vehicles must meet the emission standard of China 6. China will implement China $6 \mathrm{~b}$, a stricter emission standard, in 2023. In addition, China's regulations on compulsory scrapping of motor vehicles stipulate that motor vehicles' service life (except semitrailer containers and nonoperating buses) shall not exceed 15 
TABLE 4: Development of emission standards for passenger cars in Europe and China.

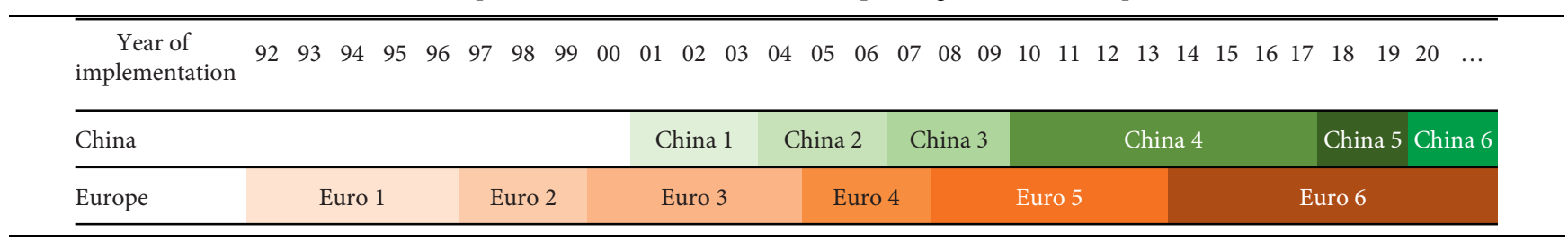

years. In other words, all vehicles should at least meet the China 6 (Euro 6) emission standard in 2035.

Therefore, we can boldly speculate that the base emission rate of Chinese vehicles in 2035 will be lower than that of the current value determined by the PIARC under the Euro 6 emission standard. Using a conservative calculation method, taking the base emission rate released by the PIARC in VEADV2019 as the base emission rate of the target year in China, a breakthrough was found for the ventilation design and calculation of the Bohai Strait. Below, we will discuss the results of the tunnel ventilation calculation under the above calculation ideas.

\section{Discussion}

\subsection{Air Demands under the New Base Emission Rates}

\subsubsection{Chinese Calculation Method and PIARC Values.} We used the base emission rates without a reduction in VEADV2019 as the base emission rates of 2035 in the ventilation calculation of the Bohai Strait Channel. In addition, the time factor $f_{t}$ was 1 in equation (4). The design concentration adopts the latest values proposed in VEADV2019. The air demand of the BSC tunnel is calculated by the method of Chinese codes. The results are shown in Figure 5.

The results show that, with the increase in vehicle speed, the air demand to dilute $\mathrm{CO}$, smoke, and dust decreases. For different periods, the long-term air demand is higher than the short-term air demand. The required air to dilute CO is the control factor, where the maximum air demand is $46.3 \mathrm{~m}^{3} / \mathrm{s}$ in 2040 in the short term and $72.6 \mathrm{~m}^{3} / \mathrm{s}$ in 2050 and $88.6 \mathrm{~m}^{3} / \mathrm{s}$ in 2060 in the long term.

According to the calculation, the cross-sectional wind speed that meets the short-term air demand is $0.45 \mathrm{~m} / \mathrm{s}$, while for the long-term air demand, it is $0.72 \mathrm{~m} / \mathrm{s}$. This means that longitudinal ventilation without shafts can meet the specification requirements under normal traffic conditions.

In general, based on the base emission rates and design concentration values from VEADV2019, as well as the calculation methods from Chinese codes, the wind speed of longitudinal ventilation for the BSC tunnel can meet the ventilation needs.

5.1.2. PIARC Calculation Method and PIARC Values. Similarly, the base emission rate in VEADV2019 was directly taken as the base emission rate in 2035, and the latest design concentration values proposed by the PIARC in 2019 were also adopted. We utilized the calculation methods from the
PIARC to determine the air demand, and the calculation result is shown in Figure 6.

Figure 6 shows that, with increasing vehicle speed, the air demand to dilute $\mathrm{CO}$ decreases first and then increases slightly. The minimum air demand appears at the vehicle speed of $60 \mathrm{~km} / \mathrm{h}$, and the maximum air demand appears at the vehicle speed of $80 \mathrm{~km} / \mathrm{h}$. The air demand to dilute smoke and dust decreases with increasing vehicle speed.

The calculation results show that the short-term air demand is controlled by the air demand to dilute smoke and dust in 2040 , which is $32.0 \mathrm{~m}^{3} / \mathrm{s}$. This is $69.6 \%$ of the previous result calculated by the Chinese calculation method but using PIARC values. In the long term, the air demand in 2050 is controlled by the air demand to dilute $\mathrm{CO}$ at $80 \mathrm{~km} / \mathrm{h}$ and is $50 \mathrm{~m}^{3} / \mathrm{s}$. In 2060, the air demand is $60 \mathrm{~m}^{3} / \mathrm{s}$, which is required to dilute $\mathrm{CO}$; this is also almost $70 \%$ of the value calculated using the Chinese method.

The cross-sectional wind speed for meeting the shortterm air demand is $0.31 \mathrm{~m} / \mathrm{s}$, while it is $0.58 \mathrm{~m} / \mathrm{s}$ in the long term air demand. Therefore, under normal traffic conditions, the ventilation design without shafts can meet the specification requirements.

In general, by adopting values from VEADV2019, the calculation shows that the longitudinal ventilation design without shafts can meet the ventilation requirements using China and PIARC calculation methods.

5.2. Growth of New Energy Vehicles. With the appearance of new energy vehicles, pollution emissions greatly decrease. Consequently, the burden of tunnel ventilation is lightened. Although the pollution problem has been alleviated greatly to date, new challenges about disaster prevention and rescue in tunnels are arising.

By the end of 2019, the number of electric vehicles in China had reached 3.81 million, accounting for 1.46 percent of the total and an increase of 1.2 million or $46.05 \%$ from the end of 2018 [21]. According to the proposed report released by the Chinese government, the New Energy Vehicles Industry Development Plan (2021-2035) [22], the proportion of electric vehicles will increase, and they will replace fuel vehicles in the near future. There are no exhaust emissions from new energy vehicles. The proportion of new energy vehicles in the total number should be properly considered in the ventilation design of the BSC tunnel in 2035.

Based on this, we considered three scenarios with the proportion of new energy vehicles at $30 \%, 50 \%$, and $70 \%$ of the total traffic. The design values and methods were chosen from VEADV2019. Compared with the previous results, the new calculation outputs considering new energy vehicles 


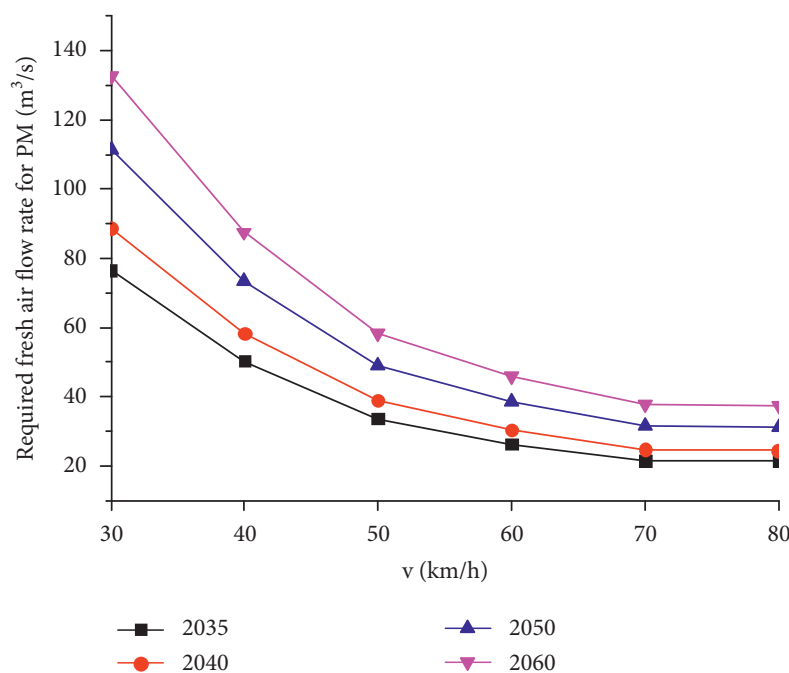

(a)

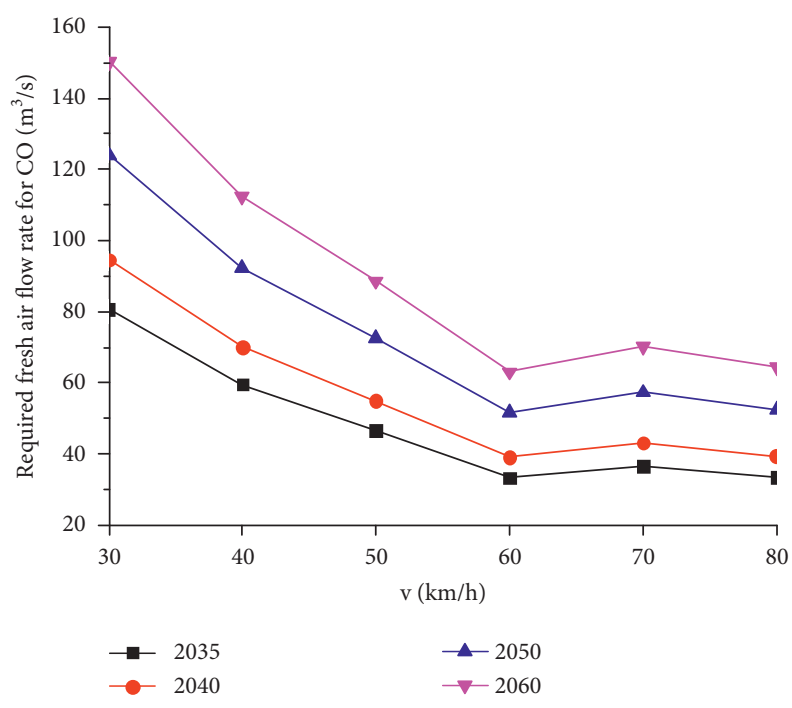

(b)

FIGURE 5: The air demands of the BSC tunnel using the Chinese method and PIARC values. (a) Calculation results of $\mathrm{Q}_{\mathrm{iv}}$. (b) Calculation results of $\mathrm{Q}_{\mathrm{co}}$.

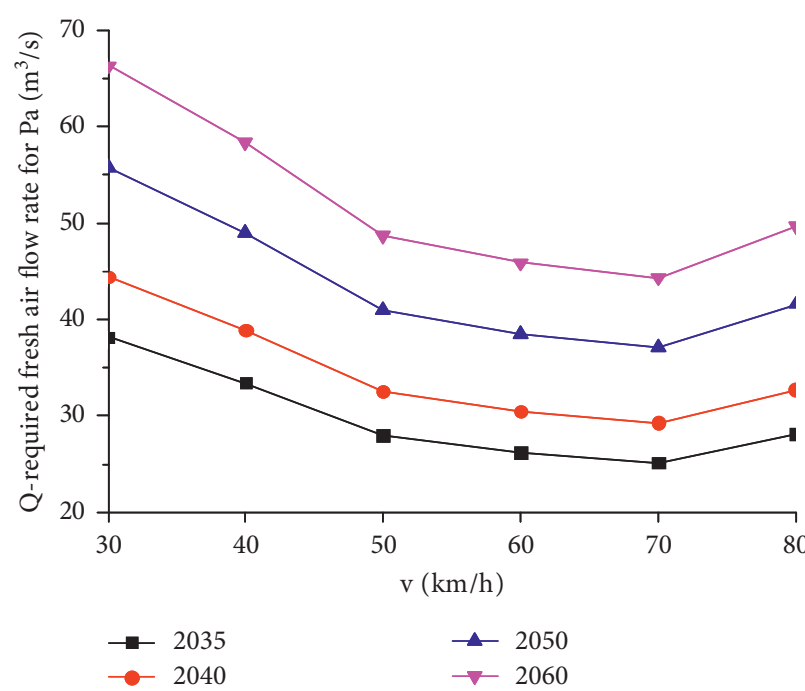

(a)

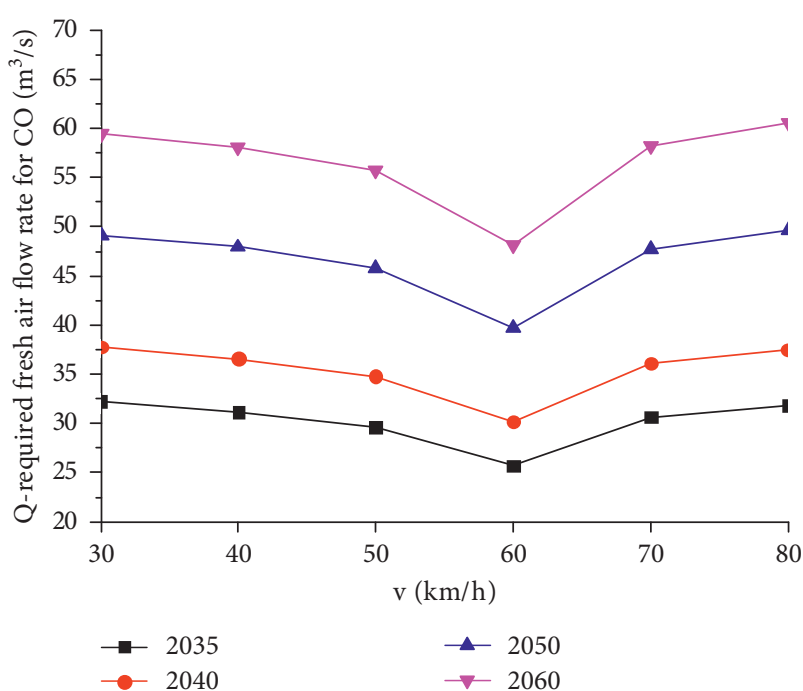

(b)

Figure 6: The air demands of the Bohai Strait Channel using the European method. (a) Calculation results of $Q_{\text {iv. }}$ (b) Calculation results of $\mathrm{Q}_{\mathrm{co}}$.

were almost the same. In return, this also reflects that emissions from cars have been very low.

However, an increase in the proportion of electric vehicles imposes higher requirements for tunnel fire ventilation and fire rescue because lithium battery fires of new energy vehicles have the characteristics of sudden fire, rapid spread, toxic smoke, explosion, and being easy to reignite. It is difficult to fire lithium batteries in a tunnel [23]. Fires caused by lithium battery electric vehicles were ranked as the main safety hazard for these vehicles $[24,25]$. We suggest that the design of BSC tunnels should consider lithium battery fires, as new energy vehicles will become more common in the future.
5.3. Ventilation Rate. The minimum ventilation rate in tunnels aims to ensure that the air is clean enough through replacement in tunnels. The PIARC pointed out in the report in 2004 that the ventilation rate in a tunnel should be more than 3 times/h or the longitudinal wind speed of the tunnel should be more than $1.5 \mathrm{~m} / \mathrm{s}$, which is the same as the specifications in the Chinese code. However, due to the release of more stringent emission standards, the tunnel's air quality has been greatly improved. Therefore, in the 2012 report [19], PIARC pointed out that, for a longitudinal ventilation tunnel, the speed of longitudinal air should be controlled between $1.0 \mathrm{~m} / \mathrm{s}$ and $1.5 \mathrm{~m} / \mathrm{s}$ and indicated that the ventilation rate should be considered only under special 
circumstances instead of normal conditions. Furthermore, in VEADV2019, the PIARC canceled the requirements for ventilation rate and longitudinal air speed.

The BSC tunnel is expected to be built in 2035. Future vehicles will meet more stringent emission standards, whereby the emission of pollutants in the tunnel will be greatly reduced. After calculations, if we insist on the ventilation rate from Chinese codes, there will be great waste due to considering the number of air changes as the design index. Instead, for the previously presented reasons and trends, we suggest that the BSC tunnel does not need to consider the ventilation rate under normal conditions.

\section{Conclusion}

The construction of the Bohai Strait Channel will form a convenient traffic net and contribute to China's economy. Due to limitations, the BSC tunnel cannot adopt ventilation shafts. The longitudinal ventilation design for the BSC tunnel cannot meet the requirements under current Chinese codes.

In this paper, we present the development of emission standards, which will heavily affect the tunnel's ventilation design system. The comparison results between Chinese emission standards and the EU emission standards showed that China has caught up with European emission standards in the past 20 years. However, the base emissions in Chinese codes have not yet been updated. Here, we suggested adopting the base emission rates reported by the PIARC in 2019 as the base emission rates for the target year 2035. To achieve a stricter design, design concentration values that are more conservative than those specified by the PIARC were used.

The trial calculation results show that the longitudinal ventilation scheme without shafts is feasible, with the values from the PIARC instead of Chinese codes. Furthermore, the influences of new energy vehicles and the ventilation rate on tunnel ventilation are discussed. We suggest considering the fire situation of new energy vehicles and not considering the ventilation rate for the BSC tunnel. We hope to provide a reference for BSC tunnel ventilation design and the improvement of ventilation specifications and emission standards in China.

\section{Abbreviations}

In Chinese code:

$Q_{\mathrm{CO}}$ : Volume of $\mathrm{CO}$ emissions in the whole tunnel

$q_{\mathrm{CO}}: \quad$ CO base emissions for target year

$f_{a}$ : $\quad$ Road condition factor

$f_{d}$ : $\quad$ Vehicle density factor

$f_{h}: \quad$ Altitude factor

$f_{m}: \quad$ Vehicle type factor

$f_{i v}: \quad$ Slope-speed factor

$L: \quad$ Length of the tunnel

$n$ : $\quad$ Number of vehicles' type

$N_{m}: \quad$ Traffic volume of one type of vehicle

$q_{\text {Euro-Chi }}$ : Conversed base emission rate

$\rho_{c o}: \quad$ Density of $\mathrm{CO}$

$v: \quad$ Design speed.
In $E U$ code

$G_{\text {tun }}$ : Volume of CO emissions in the whole tunnel

$N_{\text {sec }}$ : Number of longitudinal sections of tunnel

$N_{\text {lane }}: \quad$ Number of tunnel lanes

$G_{\text {sec }, j}: \quad C O$ emissions in a single lane with a longitudinal slope

$g_{\mathrm{fac}, i}: \quad$ Base emission rates of a certain vehicle under different speeds and different slopes

$n_{\mathrm{veh}, i}$ : The traffic volume corresponding to the vehicle

$f_{t}:$ The time factor

$f_{m}: \quad$ Mass factor

$f_{a}: \quad$ Altitude factor

$g_{\text {non-ex }}:$ Nonexhaust emissions

$Q_{\mathrm{CO}, i}$ : Volume of $\mathrm{CO}$ emission of the corresponding longitudinal slope.

\section{Data Availability}

The data presented in this study are available upon request from the corresponding author. The data are not publicly available due to privacy.

\section{Conflicts of Interest}

The authors declare that they have no known competing financial interests or personal relationships that could have appeared to influence the work reported in this paper.

\section{Acknowledgments}

This research paper was financially supported by the Consulting and Research Project of the Chinese Academy of Engineering (2019-ZD-7), National Natural Science Foundation of China (Grant no. 51478473), and Science and Technology Research Project of China Railway Corporation (Grant K2018G019). The authors thank all participating units and scholars involved in the "Preliminary Strategic Research of the Bohai Strait Channel Project." In this paper, the construction scheme, ventilation design, and some other relevant materials come from this project. The authors truly appreciate their partners' support. Without their help and the inspiration of their research, it would have been difficult to complete this paper. If there are any shortcomings in the paper, please criticize and correct them.

\section{References}

[1] Z. Wang, G. Xu, C. Bao, J. Xu, and F. Sun, "Spatial and economic effects of the Bohai Strait cross-sea channel on the transportation accessibility in China," Applied Geography, vol. 83, pp. 86-99, 2017.

[2] C. Xing, Z. Qian, C. Xuefeng, and L. Yongqing, "Summertime bottom water transports in the Bohai Strait, China," Regional Studies in Marine Science, vol. 35, Article ID 101210, 2020.

[3] S. Mei, H. X. Chu, L. Y. Dong et al., "Influencing factors and evaluation application of regional crustal stability in the Bohai Strait," China Geology, vol. 2, no. 3, pp. 354-363, 2019.

[4] Q. Liu, X. Huang, Q. Gong, L. Du, Y. Pan, and J. Liu, "Application and development of hard rock TBM and its 
prospect in China," Tunnelling and Underground Space Technology, vol. 57, pp. 33-46, 2016.

[5] O. T. Blindheim, "Learning from the lærdal tunnel," Tunnels and Tunnelling International, vol. 35, no. 10, 2003.

[6] M. N. Wang, Y. Qi-xin, and Z. Yan-hua, "Study on qinling zhongnanshan extra-long highway tunnel network ventilation system," Journal of Highway and Transportation Research and Development, vol. 19, no. 4, pp. 65-68, 2002.

[7] M. Bettelini, H. Neuenschwander, A. Henke, M. Gagliardi, and W. Steiner, "The fire in the st gotthard tunnel of october 24, 2001," SP Rapport-Statens Provningsanstalt, pp. 49-68, 2004.

[8] R. Arditi, F. Joel, and J. Ugo, "Risk management applied to the Frejus tunnel," Routes/Roads, 330 pages, World Road Association (PIARC), Paris, France, 2006.

[9] U. Drost, The Ventilation and Security in Long Road Transalpine Tunnels, World Road Association (PIARC), Paris, France, 2012.

[10] A. Waltl and F. Michelitsch, "Experiences with the safety and ventilation design in operation of the Plabutsch tunnel: na," in Proceedings of the 3rd International Conference 'Tunnel Safety and Ventilation', Graz, Austria, January 2006.

[11] S. Jun, "Reflections on construction of Bohai bay crossing corridor," Chines journal of Tunnel Construction, vol. 38, no. 11, pp. 1753-1764, 2018.

[12] W. Mengshu, "Current developments and technical issues of underwater traffic tunnel-discussion on construction scheme of taiwan strait undersea railway tunnel," Chinese Journal of Rock Mechanics and Engineering, vol. 11, pp. 2161-2172, 2008.

[13] L. Chunfang, "Maintenance and repair mode and technologies for high speed railway bridges and tunnels," Chinese Jornal of China Railway, vol. 7, pp. 1-08, 2017.

[14] S. Yongfu, H. He, J. Zheng, Z. Lin, Y. Yang, and Y. Tian, "Research on China rggs," Chinese Journal of Engineering Science, vol. 19, no. 5, pp. 1-08, 2017.

[15] L. Yu, J. Wu, A. Zhou, E. G. Larsson, and P. Fan, "Massively distributed antenna systems with non-ideal optical fiber fronthauls: a promising Technology for $6 \mathrm{G}$ wireless communication systems," IEEE Vehicular Technology Magazine, vol. 15, 2020.

[16] L. Yu, H. Zhang, L. Zhang, L. Song, and P. Fan, "Hypergraphbased SCMA codebook allocation in user-centric ultra-dense networks with machine learning," in Proceedings of the 2019 11th International Conference on Wireless Communications and Signal Processing (WCSP), Xi'an, China, October 2019.

[17] Yu Li and X. Ha, "GIS-based study on the Bohai Strait crosssea channel route scheme," in Proceedings of the 6th International Conference on Energy, Environment and Sustainable Development (ICEESD 2017), Zhuhai, China, March 2017.

[18] China, Ministry Of Transport Of People's Communications Press Co., Ltd, Guidelines for Design of Ventilation of Highway Tunnels, China, Ministry Of Transport Of People's Communications Press Co., Ltd, Beijing, China, 2014.

[19] Association, World Road, Road Tunnels: Vehicle Emissions and Air Demand for Ventilation, 61 pages, World Road Association (PIARC), Paris, France, 2019.

[20] Association, Piarc World Road, Road Tunnels: Vehicle Emissions and Air Demand for Ventilation, World Road Association (PIARC), Paris, France, 2004.

[21] J. Li, J. Jiao, Y. Xu, and C. Chen, "Impact of the latent topics of policy documents on the promotion of new energy vehicles: empirical evidence from Chinese cities," Sustainable Production and Consumption, vol. 282 pages, 2021.
[22] China, Ministry Of Industry, New Energy Vehicles Industry Development Plan (2021-2035), China, Ministry Of Industry, Beijing, China, 2019.

[23] W.-t. Luo, S.-b. Zhu, J.-h. Gong, and Z. Zhou, "Research and development of fire extinguishing Technology for power lithium batteries," Procedia engineering, vol. 211, pp. 531-537, 2018.

[24] B. D. Ehrhart, D. M. Brooks, A. B. Muna, and C. B. LaFleur, "Risk assessment of hydrogen fuel cell electric vehicles in tunnels," Fire Technology, vol. 56, pp. 1-22, 2019.

[25] J. Sun, H. Zhang, and F. Xiang, "Challenges of new energy vehicles in tunnel fire and discussion on emergency rescue Technology," in Proceedings of the 7th International Conference on Informatics, Environment, Energy and Applications, Beijing China, March 2018. 